\title{
"Being fat is not a disease but a sign of good living": The Political Economy of Overweight and Obesity in Nigeria
}

\author{
Tolulope Osayomi
}

\begin{abstract}
Increasing overweight and obesity rates have accompanied economic development in recent years. This twofold health issue has become increasingly worrisome and is currently receiving academic interest and government attention. A growing volume of studies has examined the demographic, socio economic, environmental and cultural risk factors of overweight and obesity in Nigeria where fatness is culturally revered. However, information on large scale factors associated with economic development shaping the geographical distribution of overweight and obesity is sparse. From the political economic standpoint, the central question of this paper is: 'Does the spatial pattern of overweight and obesity correspond with the varying levels of economic development in Nigeria? The study relied on secondary data from published sources. Linear regression models were estimated to determine the impact of economic development variables on overweight and obesity. Results reveal that percent population with white collar jobs had a significant positive effect on overweight whereas poverty, gross domestic product (GDP) and degree of urbanization were significantly related to obesity. The paper concludes that the spatial patterns of overweight and obesity follow the pathways of economic development in Nigeria.
\end{abstract}

Key words: Obesity, political economy, spatial analysis, medical geography, Nigeria

Department of Geography, University of Ibadan, Ibadan osayomi@yahoo.com

Ghana Journal of Geography Vol. 12(1), 2020 pages 99- 114

https://doi.org/10.4314/gig.v12i1.5 


\section{Introduction}

Overweight and obesity refer to the excessive accumulation of fat in the human body which has adverse consequences on individual health, well-being and quality of life (Alexander, 2016). Like most non-communicable diseases (NCDs), they are multifactorial conditions caused by a multitude of factors such as unhealthy diets, physical inactivity, alcohol consumption etc (Agyemang et al. 2015; Lakerveld and Mackenbach, 2017). Though preventable, overweight and obesity are on the rise. In 2016, more than 1.9 billion people were overweight. Of these, over 650 million were obese (WHO, 2019). The rapid increase in prevalence is being experienced in low and medium countries (LMICs) (Ford et al 2017), and the globalization of western lifestyle and diets has been blamed for it (Fumagalli et al 2013).

Though shaped by global influences and local contexts, in the literature the rise in overweight and obesity is attributed to a number of explanations, namely the individual-lifestyle-perspective, the obesogenic-environment perspective and the symbolism-of-obesity perspective. The individuallifestyle perspective is of the view that obesogenic behaviour is the result of individual level risk factors, choices that increase body mass such as genetic susceptibility, unhealthy diets, and excessive alcohol intake (Hajizadeh et al 2016; Lakerveld and Mackenbach, 2017). It is believed that the prevalence of overweight and obesity is a function of the degree to which the human population is exposed to these predisposing risk factors. If the condition is to be prevented or controlled, the individual must make some choices.

Secondly, the obesogenic environment perspective posits that "[o]besity is the result of a mutual interaction between an obesity promoting environment and the human population" (Osayomi, 2018, p.12). The environment in which we live and work, to a certain extent, encourages overweight and obesity, particularly in urban areas where there is a shift from traditional diets to refined meals coupled with improved food access, high disposable income, infrastructural development etc. (Ford et al 2017; Ajayi et al 2016, Agyemang et al. 2015), strong dependence on motorized transport, and infrequent physical activity. No doubt, urbanization represents a largescale societal factor underlying the spatial patterns of NCDs (Pou et al. 2017). Just as obesity is the outcome of the urban environment, so is it a product of broader economic and political 
environments (Swinburn et al 2011). Economic success is accompanied by the overweight and obesity burden (Alexander et al 2016), and rapid economic growth has facilitated the spread of western lifestyles, especially the consumption of refined foods (Doku and Neupane, 2015) to territories of non-western cultures.

The last explanation is the symbolism-of-obesity perspective. This perspective portrays overweight/obesity as a hall mark of affluence. It implies that being overweight or obese suggests strong economic well-being and progress in life. As Osayomi $(2019 ; 1160)$ puts it, "an obese individual is frequently perceived to be well nourished, financially comfortable and erroneously assumed to live a stress-free life". In other words, a person with a slim frame is portrayed as being impoverished; terminally ill and without dignity (Osayomi and Orhiere, 2017; Pus et al 2016). In addition, the worldviews or social constructions among some racial/ethnic groups such as the Yoruba, Igbo and Efik of Nigeria, glorify large body size (Ibrahim and Jegede, 2017; Oe, 2009; Brink, 1989, Osayomi and Orhiere, 2017). For instance, large body size among the Yoruba ethnic group symbolizes İfọànbale (peace of mind) and is often couched in proverbial expressions which connote the cultural acceptance of fatness, such as ara sísan ki s'àrùn (fatness is not illness) (Ibrahim and Jegede, 2017b). Among married Yoruba women too (Ibrahim and Jegede, 2017a), as well as among the Efik speaking women (Oe, 2009), large body size is a strong indicator of marital welfare . In faraway Papua New Guinea, fat people, based on traditions and cultural values, are socially acceptable because they are perceived to be healthy. In the same cultural context, being skinny confers little recognition (Pus et al 2016). In summary, being fat, to these cultural groups, is not a disease but evidence of good living.

Though there are individual-level drivers, the effects of distal factors such as socio-economic changes are glossed over in the causation of the twin epidemic (Gracia-Arraiz et al 2017). As earlier stated, economic prosperity triggers high rates of overweight and obesity. As a matter of fact, they have been labelled "diseases of affluence". According to Wang et al (2017), the rise in disposable incomes increases food supply and calorie intake and reduces physical activity. Therefore, the economic context is responsible for the formation of obesogenic environments. 
In Nigeria where obesity is an emerging public health problem (Akaraolo et al 2014), studies have mainly focused on environmental, behavioural, cultural and population drivers of the increased body size (Kandala and Stranges, 2014; Akaraolo et al 2014; Osayomi and Orhiere, 2017). Studies on the political economy of overweight and obesity in Nigeria are sparse. Thus, there are no insights as to the politico-economic determinants of overweight and obesity in Nigeria. Although the relationship between socio-demographic factors and overweight and obesity has been established, the study strives to examine, for the first time, in Nigeria, the spatial pattern of overweight and obesity within the context of economic development.

The study is informed by the political economy perspective on the geography of health and disease which posits that "... [the] causes of diseases are rooted in political and economic systems rather than individual lifestyles and behaviours" (Gatrell, 2002:39); again “... though the immediate cause of a disease may be a virus or a carcinogen, the institutions and practices of society are largely responsible for creating the conditions or context under which humans and disease-causing agents interact" (Gesler, 1997: 659-660). Informed by this theoretical framework, the fundamental question of this study is thus 'Does the spatial pattern of overweight and obesity correspond with the varying patterns of economic development in Nigeria?' This enquiry would certainly provide some insights into large scale determinants of this dual epidemic in the Nigerian context.

\section{Data and Methods}

Data used in the study were extracted from the following sources: the Nigerian Demographic and Health survey (NDHS) Report of 2008, the 2009/2010 Harmonized Living Standards Survey Report and the UNDP country report of 2009. The NDHS provided information on state level prevalence of overweight and obesity among women aged 15 to 49 . They served as surrogates for overweight and obesity. Data on the percentage of the population with white-collar jobs originated from the 2009/2010 Harmonized Living Standards survey report. The UNDP Report 2009 offered information on state GDP per capita, Human Development Index (HDI), Human Poverty Index (HPI) and number of manufacturing industries per state. Due to the dearth of data on the level of urbanization in Nigeria, particularly at the state level, population density (the ratio of a state's population to its area in square kilometres) was computed as the degree of urbanization per state. 
It is assumed that the higher the state averages, the higher the degree of urbanization would be. The population of the thirty-six states and Federal Capital Territory was based on the 2006 Population Census conducted by the National Population Commission. The operationalization of the variables is set out in Table 1.

Table 1: Study variables, their sources and description

\begin{tabular}{|c|c|c|}
\hline Variables & Description & Source \\
\hline Overweight & Percent of women with BMI of $25-29 \mathrm{~kg} / \mathrm{m}^{2}$ & NDHS, 2008 \\
\hline Obesity & Percent of women with BMI of 30 and above $\mathrm{kg} / \mathrm{m}^{2}$ & NDHS, 2008 \\
\hline White Collar jobs & $\begin{array}{l}\text { Percent of state population engaged in white collar } \\
\text { jobs }\end{array}$ & $\begin{array}{l}\text { HNLS, } 2009 / 2 \\
019\end{array}$ \\
\hline $\begin{array}{l}\text { Manufacturing } \\
\text { industries }\end{array}$ & Number of manufacturing industries & UNDP, 2009 \\
\hline GDP per capita & State GDP per capita & UNDP, 2009 \\
\hline Urbanisation & Population density per state & $\begin{array}{l}\text { Computed by } \\
\text { author }\end{array}$ \\
\hline Poverty & Human Poverty Index & UNDP, 2009 \\
\hline Development & HDI & UNDP, 2009 \\
\hline
\end{tabular}

Source: Compiled by Author

Global Moran's I is a common measure of spatial autocorrelation developed by Moran (1948). It tells the degree to which an object clusters or disperses in geographical space. Moreover, it specifically indicates the nature of the spatial autocorrelation. Zero autocorrelation means no spatial autocorrelation; -1 means negative spatial autocorrelation while +1 signifies positive spatial autocorrelation. This spatial autocorrelation analysis was possible with the aid of GeoDa 1.21.1.131 (April 2018).

Pearson correlation coefficients were computed to measure the degree of relationship between overweight and obesity and the potential causal factors. Later, a stepwise regression approach was used to identify the most significant factor(s) and quantify impact(s) on the spatial variation in overweight and obesity. These analyses were done using the Statistical Package for the Social Sciences (SPSS) Version 20. 
Ghana Journal of Geography Vol. 12(1), 2020 pages 99- 114

\section{Results}

Summary statistics are set out in Table 1. Based on the standard deviation values, wide variations are seen in manufacturing, GDP per capita and urbanization only (Table 1).

Table 1: Summary statistics

\begin{tabular}{lll}
\hline Variable & Mean & Standard deviation \\
\hline Overweight (OW) & 15.55 & 5.97 \\
Obesity (OB) & 5.67 & 2.93 \\
White collar jobs (WC) & 15.00 & 8.23 \\
Manufacturing (MAN) & 1255.06 & 45381 \\
GDP per capita (GDP) & 1304.95 & 1993.03 \\
Urbanization (URB) & 303.35 & 416.03 \\
HDI & 0.47 & 0.10 \\
HPI & 34.16 & 11.33 \\
\hline
\end{tabular}

Source: Data analysis

\section{Spatial pattern of overweight and obesity}

The overall prevalence for overweight and obesity is $15.6 \%$ and $5.7 \%$ respectively (Table 1 ). Overweight varies geographically. It was remarkably high in Enugu (26.9\%). Lagos (26.3\%), FCT (25.8\%), Anambra (24.7\%), Edo (23.7\%) and Imo (22.4\%), whereas the lowest prevalence was found in four northern states, namely Sokoto (5.4\%), Yobe (6.8\%), Gombe (7.5\%) and Bauchi (7.5\%). Like overweight, there is an uneven distribution in the obesity prevalence. Anambra (13.5\%), Lagos (12.4\%), FCT (10.8\%) and Rivers (10.7\%) have the highest obesity prevalence while Bauchi (1.5\%), Kano (1.6\%), Yobe (2.2\%) and Osun (2.3\%) states have the lowest figures (Figure 1). 


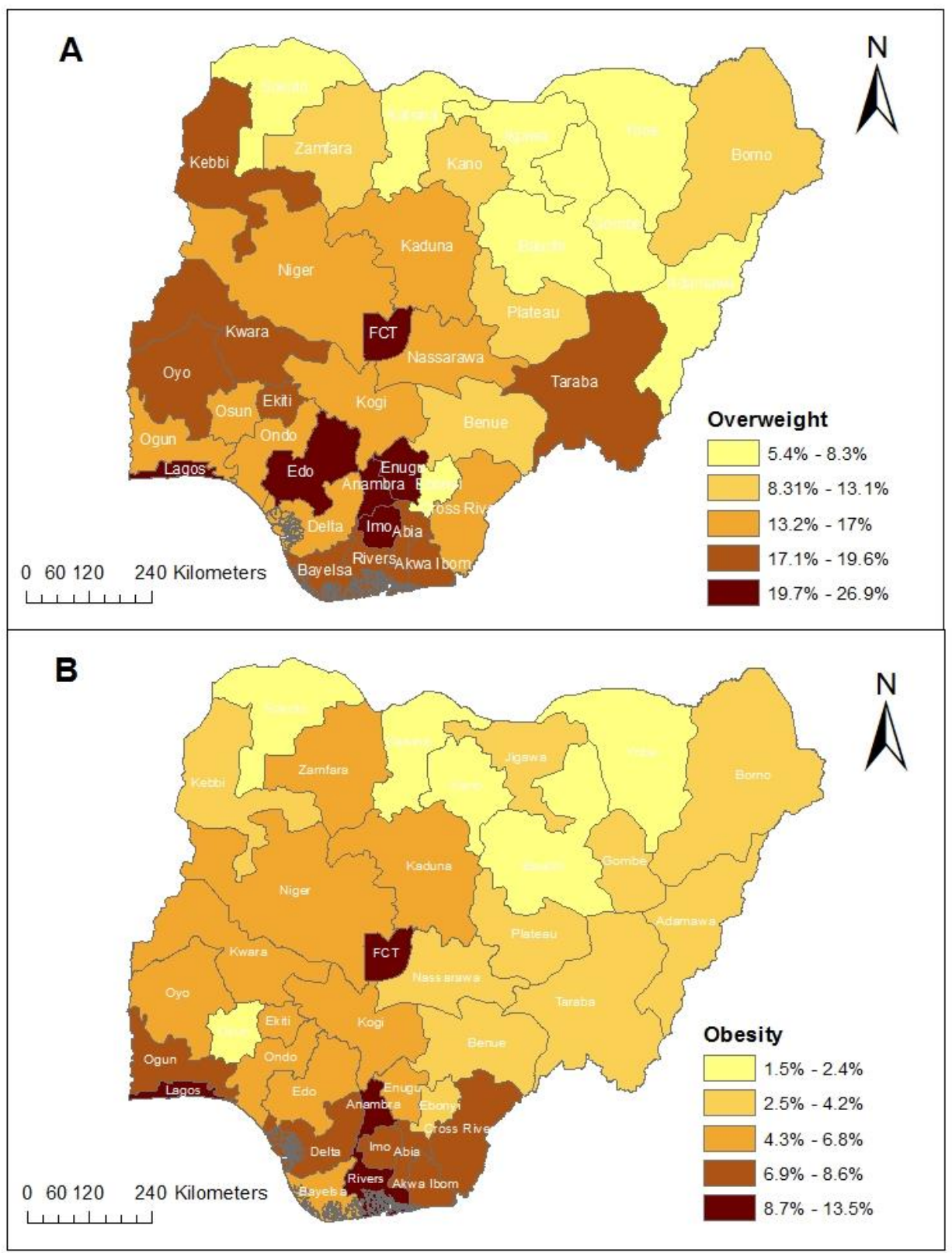

Figure 1: Spatial Patterns of Overweight and Obesity in Nigeria

The analysis shows that there is evidence of positive spatial autocorrelation between overweight $(\mathrm{I}=0.3315 ; z=3.0729 ; \mathrm{p}=0.002)$ and obesity $(\mathrm{I}=0.4622 ; z=4.4541 ; \mathrm{p}=0.002)$. This of course means that each of these two health conditions clusters in space. The Moran scatter plots indicate positive 
spatial autocorrelation. They illustrate that states with high or low overweight/obesity prevalence are near other states with similar values (see Figures 2 and 3)

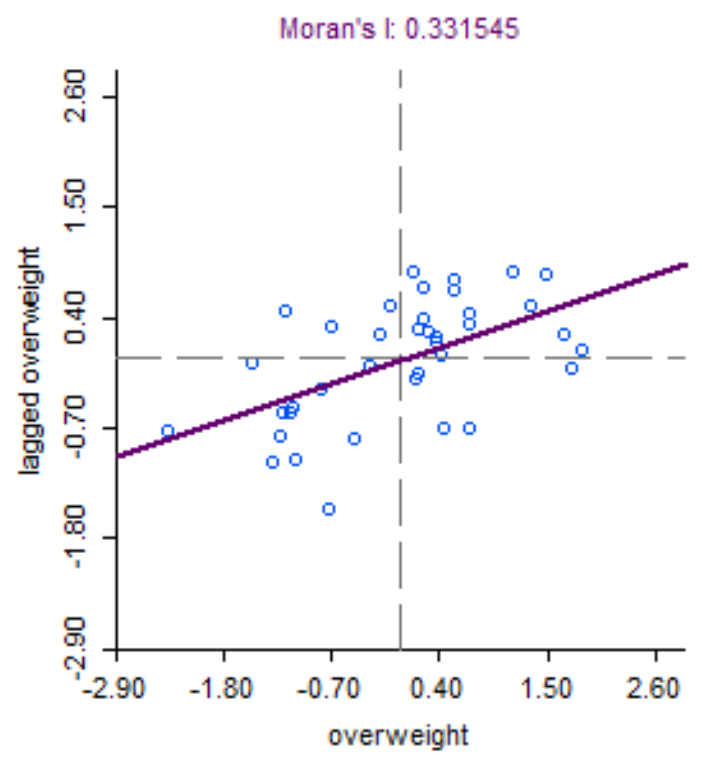

Figure 2: Moran's Scatter Plot for Overweight

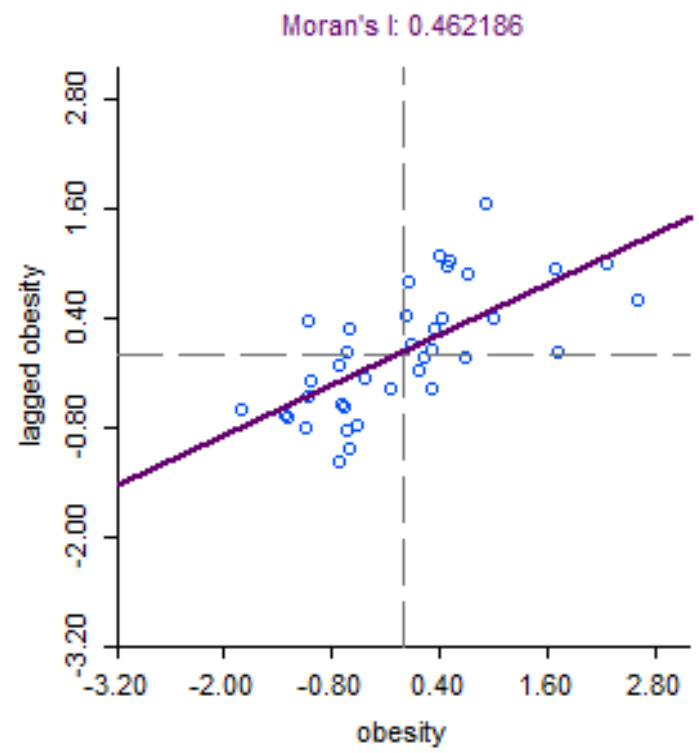

Figure 3: Moran's Scatter Plot for Obesity

Table 2 shows the results of bivariate correlation. On the one hand, overweight is significantly and directly related to HDI, white collar jobs, manufacturing, GDP per capita and urbanization, and is inversely associated with HPI. On the other hand, obesity has significant positive associations with 
HDI, white collar jobs, manufacturing, GDP per capita and urbanization, and a significant negative relationship with HPI.

Table 2: Correlation Coefficients

\begin{tabular}{lll}
\hline Variable & Overweight & Obesity \\
\hline HDI & $0.601 * *$ & $0.633^{* *}$ \\
HPI & $-0.699 * *$ & $-0.721^{* *}$ \\
White collar jobs & $0.750^{* *}$ & $0.714^{* *}$ \\
Manufacturing & $0.387 *$ & $0.496 * *$ \\
GDP per capita & $0.349 *$ & $0.440^{* *}$ \\
Urbanisation & $0.471^{* *}$ & $0.577^{* *}$ \\
\hline
\end{tabular}

** Significant at $0.01 ; *$ significant at 0.05

The population with white collar jobs accounts for 56.2 percent of the variance in overweight while HPI, GDP and urbanization collectively contribute 64.2 percent of the variance in obesity (Table 3). Therefore, white collar jobs is a significant factor influencing the spatial distribution of overweight while HPI, GDP and urbanization are significant correlates of obesity in the country.

Table 3: Summary of regression results

\begin{tabular}{llllrl}
\hline Predictor & $\mathrm{R}^{2}$ & $\begin{array}{l}\text { Adjusted } \\
\mathrm{R}^{2}\end{array}$ & Regression model & $\mathrm{F}$ & $\begin{array}{l}\mathrm{p} \\
\text { value }\end{array}$ \\
\hline Overweight & 0.562 & 0.550 & $7.388+0.75 \mathrm{WC}$ & 44.926 & 0.00 \\
Obesity & 0.642 & 0.609 & $\begin{array}{l}8.935- \\
0.496 \mathrm{HPI}+0.269 \mathrm{GDP}+0.287 \mathrm{URBAN}\end{array}$ & 19.693 & 0.00 \\
& & & & \\
\hline
\end{tabular}

Source: Author

\section{Discussion}

The paper examined the spatial patterns of overweight and obesity within the politico-economic context of Nigeria. The twin epidemic appears to have a higher prevalence in the south than in the 
north. The regional differential likely reflects the variations in urbanization development, and western lifestyle in the country (Akpan and Ekpenyong 2013). This view is corroborated by Kandala and Stranges (2014). Enugu and Anambra had the highest overweight and obesity prevalence respectively in the country. A plausible explanation for the high prevalence in these two southeastern states, though cultural in nature, is the 'glorification of the large body size'. According to Ijoma et al (2019), it is the belief in southeast Nigeria that people, particularly women and children, should be well-fed and fat so as to confer dignity on the family to which they belong. This corresponds with a similar belief in North Africa where "female fatness is a sign of social status and a cultural symbol of beauty, fertility and prosperity" (Mokhtar et al 2001:888)

Using a spatial analytical approach, the study discovered that there was a clustering of overweight and obesity in geographic space. Higher overweight rates, on the one hand, are significantly related to the higher proportions of population with white collar jobs. It is a well-known fact that white collar jobs are generally sedentary in nature. Oyewole and Atinmo (2015; 462-463) graphically observe:

the working environment is made conducive to keep energy instead of burning it. Workers use chairs with rollers to move from one end to another without standing up; have unlimited access to coffee drinks and soda; use intra-phone/intercom to communicate with co-workers in the next office; many manually operated machines are now digitalised and climbing staircases has given way to using the office lift, even when the destination is the next floor!

On the other hand, lower obesity rates are associated with lower poverty rates while higher obesity rates are related to higher levels in urbanization and GDP. The explanation for the negative association between poverty and obesity is that poor households, in relative terms, cannot afford energy dense foods in Nigeria. Eating out is now a popular culture in Nigeria, particularly among the middle-income earners and the wealthy who have the purchasing power (Olutayo and Akanle, 2009; Maiyaki and Garbati, 2014). Another reason for the negative relationship is the nonsedentary occupations of the urban poor and the rural dwellers in Nigeria. These two categories of people are often involved in physically active occupations. For instance, the urban poor engage in informal sector activities as street vendors/hawkers and artisans, among others, while the rural poor are mainly farmers. This is contrary to what obtains in other parts of the world where low 
income households consume more highly processed food rich in fat, sugar and salt than other income groups (Papas et al 2015; Wang et al 2017, Żukiewicz-Sobczak et al. 2014) because of its availability and affordability. This stems from the fact that regular and healthier food options are 'a thing of luxury' for the urban poor, many of whom are unemployed, physically inactive and of low educational status (Żukiewicz-Sobczak et al 2014). In fact, these mixed results on the nature of the relationship between obesity and poverty has given rise to the "poverty-obesity paradox" (Salmasi and Celidoni, 2017).

The observed relationship with GDP is an established fact in the literature. Higher national income increases food supply and consumption, boosts vehicular movements and reduces opportunities for physical activity (Wang et al 2017). This is in agreement with Wang et al (2017) and Pisa and Pisa (2017). However, this positive correlation with GDP is often noticed only in low income countries whereas the trend is entirely different in the medium and high-income countries where an inverse relationship exists (Wang et al 2017; Pampel et al.2012). Pampel et al (2012) attribute it to the influence of public health education on proper body size, weight stigmatization towards obese people and the attraction for thin body frames. This, again, contradicts what is commonly observed in lower income countries and deeply cultural societies such as Nigeria, as it was earlier stressed.

The finding on the positive association between obesity and urbanization is not far-fetched. Obesity is a side-effect of urbanization (Dempsey et al 2018). According to the Population Reference Bureau (2019), half of Nigeria's population dwell in urban settlements. Moreover, Nigeria, in the words of Mabogunje (2007:4) “...has a dense network of urban centres...with tremendous challenges for the health of the residents". These urban areas are characterized by the shift from healthy homemade meals towards fast food, little or no space or opportunities for physical activity, and white-collar occupations that generally keep workers immobile (Akpan and Ekpenyong 2013). Besides these, in urban Nigeria "life is fast as home and work are disaggregated and people are compelled to sacrifice some traditional activities usually shared, one of which is eating together at home" (Olutayo and Akanle, 2009: 210). Thus, many city dwellers are constrained to pick from a range of 'ultra-processed obesogenic foods' (Popkin, 2019). The significance of urbanization to the geographical distribution of overweight and obesity is also 
confirmed by Kandala and Stranges's (2014) study of Nigeria; Osayomi and Orhiere's (2017) work on Ibadan; Emamian et al's (2017) study on regional inequalities in obesity in Iran whose national capital, Tehran has high levels of obesity due to the high degree of urbanization; and Ajayi et al's (2016) multicountry analysis.

\section{Conclusion}

This paper makes a unique contribution to the growing body of knowledge on the geography of overweight and obesity in Nigeria. Its specific contribution to the literature is the examination of body size within the political economy frameworks. One can easily conclude that economic development has a significant impact on the spatial patterns of overweight and obesity. The major limitation of this study is the restrictive nature of data on overweight and obesity prevalence. It was originally based on women aged 15 to 49, who are just a small fraction of the country's population. Clearly, the political economy perspective has significantly provided new insights into the underlying forces shaping the spatial patterns of overweight and obesity in Nigeria, and could help shape policy responses. In light of the above, the growing health challenge would not only require behaviour change but also innovative political and socio-economic approaches such as the introduction of 'sin taxes' on unhealthy foods so as to deter unhealthy food consumption (Reich, 2019); government subsidies on fruits and vegetables to encourage healthy eating; enforcement of workplace policies on healthy foods and physical activity at government and private establishments; as well as public policy on healthy human settlements with provisions for pedestrian friendly, walkable environments and green spaces for physical activity and outdoor recreation . 
“Being fat is not a disease but a sign of good living” Political Econ of Overweight \& Obesity, Nig.

\section{Acknowledgements}

This is a modified version of a paper presented at the $59^{\text {th }}$ Annual Conference of the Association of the Nigerian Geographers (ANG) from $4^{\text {th }}$ to $9^{\text {th }}$ November 2019 at the University of Ibadan, Ibadan, Nigeria.

\section{References}

Agyemang, C, Boatemaa, S; Frempong GA \& Atkins, A. (2015). Obesity in Sub-Saharan Africa. Metabolic Syndrome DOI.10.1007|978-3-319-12125-3_5-1

Ajayi, I.O., Adebamowo, C., Adami, H.O., Dalal, S., Diamond, M.B., Bajunirwe, F., Guwatudde, D., Njelekela, M., Nankya-Mutyoba, J., Chiwanga, F.S. and Volmink, J., (2016) Urban-rural and geographic differences in overweight and obesity in four sub-Saharan African adult populations: a multi-country cross-sectional study. BMC Public Health, 16(1), p.1126.

Akaralo-Anthony, S.N, Willet, W.C., Spielelman, D. and Adebamowo, C.A., (2014) Obesity epidemic has emerged among Nigerians. BMC Public Health, 14:1-9.

Akpan, E. E., \& Ekpenyong, C. E. (2013). Urbanization Drift and Obesity Epidemic in SubSaharan Africa: A Review of the Situation in Nigeria. European Journal of Sustainable Development, 2 (2), 141-164.

Alexander, E., Selwyn, A., Calitz, C., Yach, D., \& Wang, Y. C. (2016). Obesity: Causes and Prevalence. Encyclopedia of Food and Health, 132-136.

Brink, P. J. (1989). The fattening room among the Annang of Nigeria. Medical Anthropology, 12 (1), 131-143.

Emamian, MH; Fateh, M; Hosseanpoer, AR, Alami, A \& Fotouhi, A. (2017) Obesity and its Socioeconomic Determinants in Iran. Economics and Human Biology 26:144-150.

Dempsey, S., Lyons, S., \& Nolan, A. (2018). Urban green space and obesity in older adults: evidence from Ireland. SSM-Population Health, 4, 206-215.

Doku, D. T., \& Neupane, S. (2015). Double burden of malnutrition: increasing overweight and obesity and stall underweight trends among Ghanaian women. BMC Public Health, 15(1), 670. 
Ford, ND; Patel, S.A \& Narayan KMV (2017) Obesity in Low-and Middle-Income Countries: Burden, Drivers \& Emerging Challenges. Annual Review of Public Health 38:145-64.

Fumagalli, E., Mentzakis, E., \& Suhrcke, M. (2013). Do political factors matter in explaining under-and overweight outcomes in developing countries?. The Journal of socioeconomics, 46, 48-56.

Gatrell, A. (2002) Geographies of Health: An Introduction. United Kingdom: Wiley-Blackwell.

Gesler, W. M., Bird, S. T., \& Oljeski, S. A. (1997). Disease ecology and a reformist alternative: the case of infant mortality. Social Science \& Medicine, 44(5), 657-671.

Gracia-Arnaiz, M. (2017). Taking measures in times of crisis: The political economy of obesity prevention in Spain. Food Policy, 68, 65-76.

Hajizadeh, M., Campbell, M. K., \& Sarma, S. (2016). A spatial econometric analysis of adult obesity: evidence from Canada. Applied Spatial Analysis and Policy, 9 (3), 329-363.

Ibrahim, F. M., \& Jegede, A. S. (2017a). Tradition and Limits: Polemical Construction of Body Size among the Yoruba of Southwestern Nigeria. Journal of African American Studies, 21 (2), 236-255.

Ibrahim, F. M., \& Jegede, A. S. (2017b). Body Size in Indigenous Oral Knowledge among the Yorùbá in Southwestern Nigeria. Journal of Pan African Studies, 10(7), 156-178.

Kandala N-B, Stranges S (2014) Geographic Variation of Overweight and Obesity among Women in Nigeria: A Case for Nutritional Transition in Sub-Saharan Africa. PLoS ONE 9(6): e101103. https://doi.org/10.1371/journal.pone.0101103

Kleinert, S., \& Horton, R. (2019). Obesity needs to be put into a much wider context. The Lancet, 393(10173), 724-726.

Lakerveld, J. \& Mackenbach, J. (2017) The Upstream Determinants of Adult Obesity. Obesity Facts 10.216-222.

Mabogunje, A.L. (2007) Health Challenges of Nigerian Urbanisation. The Ninth Benjamin Oluwakayode Osuntokun Memorial Lecture. The Benjamin Oluwakayode Osuntokun Trust, Ibadan. 52pp.

Maiyaki, M. B., \& Garbati, M. A. (2014). The burden of non-communicable diseases in Nigeria; in the context of globalization. Annals of African Medicine, 13(1), 1-10. 
Moran, P. A. (1948). The interpretation of statistical maps. Journal of the Royal Statistical Society. Series B (Methodological), 10(2), 243-251.

Oe, E., 2009: The fattening rooms of Calabar- a breeding ground for diabesity. Diabetes Voice, Vol. 54, pp. 40-41.

Olutayo, A. O., \& Akanle, O. (2009). Fast food in Ibadan: an emerging consumption pattern. Africa, 79(2), 207-227.

Osayomi, T., \& Orhiere, M. A. (2017). Small-area variations in overweight and obesity in an urban area of Nigeria: The role of fast food outlets. Bulletin of Geography. Socio-economic Series, 38(38), 93-108.

Osayomi, T. (2019) The emergence of a diabetes pocket in Nigeria: the result of a spatial analysis. GeoJournal, 84(5), 1149-1164 https://doi.org/10.1007/s10708-018-9911-2

Pampel, F. C., Denney, J. T., \& Krueger, P. M. (2012). Obesity, SES, and economic development: a test of the reversal hypothesis. Social Science \& Medicine, 74(7), 1073-1081.

Popkin, B.M. (2019) Rural areas drive the global weight gain. Nature Vol 5699 May, 2019 200$\underline{201}$

Oyewole, O. E., \& Atinmo, T. (2015). Nutrition transition and chronic diseases in Nigeria. Proceedings of the Nutrition Society, 74(4), 460-465.

Pou, S. A., Tumas, N., Soria, D. S., Ortiz, P., \& del Pilar Díaz, M. (2017). Large-scale societal factors and noncommunicable diseases: Urbanization, poverty and mortality spatial patterns in Argentina. Applied Geography, 86, 32-40.

Pisa, P.T. and Pisa, N.M. (2017) Economic growth and obesity in South African adults: an ecological analysis between 1994 and 2014, European Journal of Public Health, Volume 27, Issue 3, 404-409, https://doi.org/10.1093/eurpub/ckw119

Pus, A., Moriyama, M., Uno, M., \& Rahman, M. M. (2016). Identifying Factors of Obesity in Papua New Guinea: A Descriptive Study. Health, 8(14), 1616.

Reich, R.M. (2019) Political Economy of Non-Communicable Diseases: From Unconventional to Essential, Health Systems \& Reform, 5:3, 250-256, DOI: 10.1080/23288604.2019.1609872

Salmasi, L., \& Celidoni, M. (2017). Investigating the poverty-obesity paradox in Europe. Economics \& Human Biology, 26, 70-85. 
Swinburn, B. A., Sacks, G., Hall, K. D., McPherson, K., Finegood, D. T., Moodie, M. L., \& Gortmaker, S. L. (2011). The global obesity pandemic: shaped by global drivers and local environments. The Lancet, 378(9793), 804-814.

Wang, M, Wen, X; Zhang Y; Jiang C, \& Weng, F (2017) Is economic environment associated with the physical activity levels and obesity in Chinese adults? A cross sectional study of 30 regions in China. BMC Public Health 17:701.

Zukiewicz-Sobczak, W., Wróblewska, P., Zwolinski, J., Chmielewska-Badora, J., Adamczuk, P., Krasowska, E., Zagórski, J., Oniszczuk, A., Piatek, J. and Silny, W., (2014) Obesity and poverty paradox in developed countries. Annals of Agricultural and Environmental Medicine, 21(3: 590-594 